\title{
Hundertfüßer - Chilopoda / Urinsekten - Apterygota
}

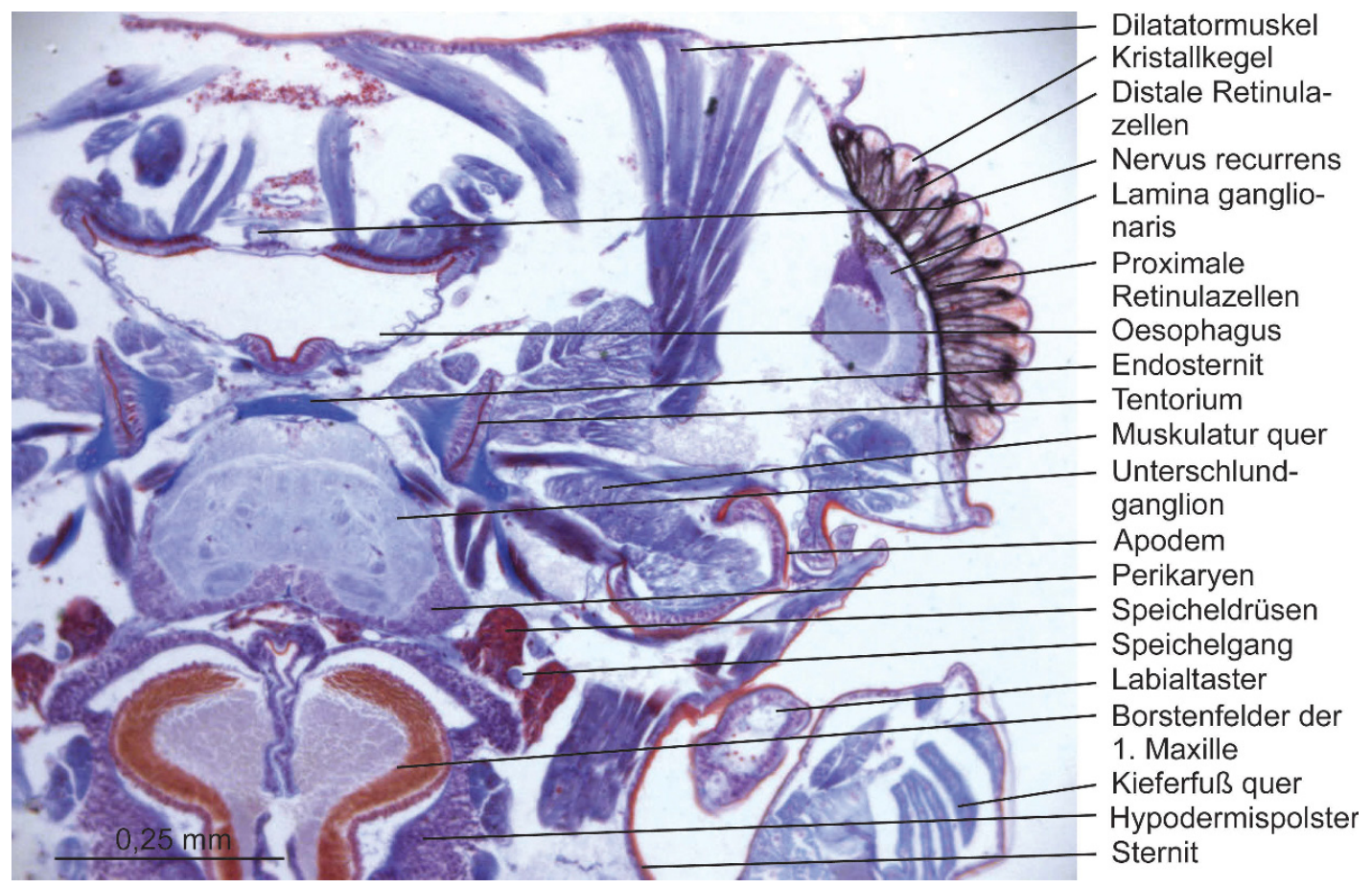

Abb. 187: Scutigera coleoptrata, Spinnenassel, Spinnenläufer: Kopfquerschnitt; Ausschnitt. Das Komplexauge von Scutigera bekommt mit jeder Häutung (8) weitere Ommatidien; erwachsene Tier haben bis zu 250 Einzelaugen. Unter einer plankonvexen Linse stehen Kristallkegel aus fünf bis neun Zellen (nicht vier wie bei Crustaceen und Insekten). Fünf bis zwölf äußere, distale Retinulazellen bilden um die Kristallkegelspitze ein Trichterrhabdom. Drei bis vier innere Retinulazellen setzen ein zweites Rhabdom dahinter. Die Augen der flinken Räuber spielen beim Fang von Milben, Collembolen, Dipterenlarven, Käfern und Blattläusen keine Rolle; nach Beute tasten die Fühler, Antennen, der "Antennata".

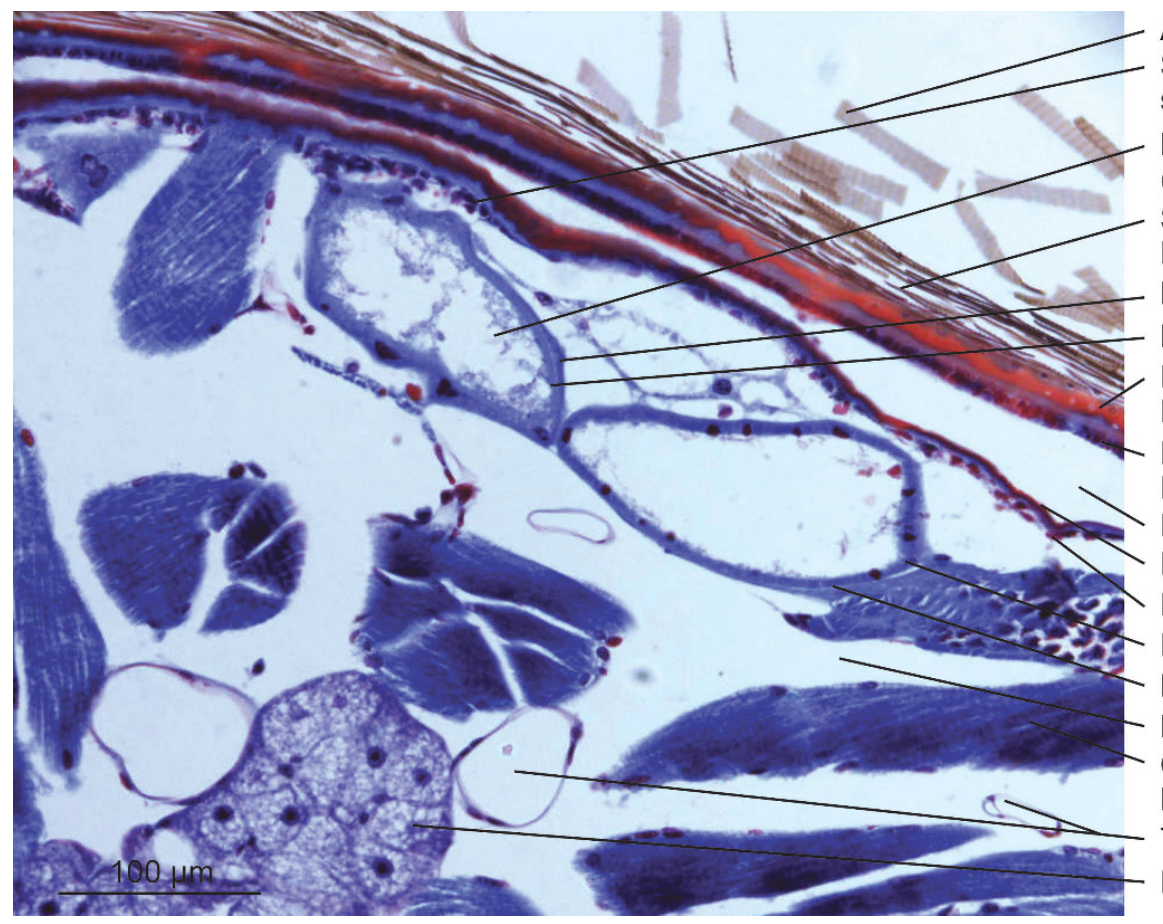

Altschuppen

Schuppenstammzellen Labialdrüse (Kopfniere) Schuppen der Exuvie Basale Labyrinthe Mikrovillisäume Exokutikula der Exuvie Endokutikula der Exuvie Exuvialspalt Prokutikula Hypodermis Drüsenepithel Basalmembran Mixocoel Quer gestreifte Muskulatur Tracheen Fettkörper

Abb. 188: Lepismachilis y-signata, Geröll-Felsenspringer: Kopfquerschnitt; Ausschnitt mit Kopfniere (Labialdrüsen). Labialdrüsen sind paarig und haben einen unpaaren Ausführgang beim Hypopharynx. Bei den primär flügellosen Apterygoten haben die Drüsen ihre ursprüngliche exkretorische und osmoregulatorische Funktion als Metanephridien anachronistisch beibehalten. Funktionsänderungen z. B. sind die Entwicklungen zu Spinndrüsen bei Hymenopteren- und Lepidopterenlarven oder zu Drüsen für blutgerinnungshemmende Sekrete bei blutsaugenden Insekten. Lipoproteine, Pektinasen und Phenolasen charakterisieren die Labialdrüsensekrete von pflanzensaftsaugenden Wanzen und Blattläusen. 